\title{
Metal-embedded SU-8 Slab Techniques for Low-resistance Micromachined Inductors
}

\author{
Manot Mapato, Prapong Klysuban ${ }^{2}$, Thanatchai Kulworawanichpong ${ }^{3}$, Nimit Chomnawang ${ }^{4}$ \\ ${ }^{1,3,4}$ School of Electrical Engineering, Suranaree University of Technology, Thailand \\ ${ }^{2}$ Synchrotron Light Research institute, Ministry of Science and Technology, Thailand
}

\begin{tabular}{l} 
Article Info \\
Article history: \\
Received Apr 1, 2017 \\
Revised May 1, 2017 \\
Accepted Mayl 7, 2017 \\
\hline Keywords: \\
High aspect-ratio \\
Metal embedded SU-8 slab \\
Micro power inductor \\
Micromachined inductors \\
X-ray lithography
\end{tabular}

Article Info

Article history:

Received Apr 1, 2017

Revised May 1, 2017

Accepted Mayl 7, 2017

\section{Keywords:}

High aspect-ratio

Micro power inductor

X-ray lithography

\begin{abstract}
This work presents new fabrication technique for micro power-inductors by using metal-embedded SU-8 slab techniques. This techniques used X-ray lithography to fabricate high aspect-ratio LIGA-like micro-structures in form of embedded structure in SU-8 slab and applied for inductor's winding fabrication with aspect-ratio of 10 . This high-aspect ratio structure can provide very low resistance winding but preserve small form factor and low profile. Inductors were designed as pot-core structures with $8 \mu \mathrm{m}$-thick permalloy core and $250 \mu \mathrm{m}$-thick copper winding. 4-types of inductors were fabricated including 3,5,10 and 16 turns in the area of $1.8 \mathrm{~mm}^{2}$ to $9.5 \mathrm{~mm}^{2}$. All inductors have overall heights of $370 \mu \mathrm{m}$, measured inductance value in a range of $70 \mathrm{nH}$ to $1.3 \mu \mathrm{H}$ at $1 \mathrm{MHz}$ and $\mathrm{DC}$ resistance value of $30 \mathrm{~m} \Omega$ to 336 $\mathrm{m} \Omega$ for 3 turns to 16 turns respectively. From this result, high aspect-ratio inductors show good results including low-resistance, high inductance, and a small form factor as expected.
\end{abstract}

Copyright $(2) 2017$ Institute of Advanced Engineering and Science. All rights reserved.

\section{Corresponding Author:}

Manot Mapato,

School of Electrical Engineering,

Suranaree University of Technology,

111 University Avenue, Nakhon Ratchasima 30000, Thailand.

Email: manot.mapato@gmail.com

\section{INTRODUCTION}

Portable electronic devices become to be daily necessities. These equipments are developed to be smaller and more efficient. However, in the limited size, these devices have only small batteries supplying energy to each circuit which requires different DC voltage levels. Thus, DC-DC converter circuit is the essential composition and determinant of these devices' efficiency. The more efficient circuits have been continuously developed. The current popularly used circuit is inductive-switching type because of its provision of great efficiency and high power density. At present, the circuit is developed at high frequency of MHz level [1]-[15]. The advantage of working at high frequency resulted in reducing passive components to be close to or smaller size than power ICs. As a consequence, passive components can be packed with ICs helping voltage converter units be smaller formfactor and lower profile [4]. In some literature, the circuits were designed to use at a high frequency of $100 \mathrm{MHz}$ [16] but the efficiency of converter circuits at high frequency was still limited to real work design which resulted from switching loss. At present, the researchers design converted circuits in the range of below $50 \mathrm{MHz}$ only. However, with limited areas, the fabrication of inductors providing efficient converter circuit at high frequency was problematic. The parameter which played an important part in determining the inductor efficiency in DC-DC converter circuit was DC resistance since the majority of current flowing through the inductors was DC current. However, with common technology, it was hardly possible to make inductors' winding using thin film technology to fabricate low resistance micro inductor by employing small areas. 
Micro-inductor's winding fabrication were generally processed with different techniques including sputtering and thermal evaporation technique possibly making metal deposition in only sub-micron level causing still high resistance winding which more suitable for high-resistance applications [17]. Thus, the researcher turned to use electroplating technique which yielded thicker windings by electroplating metal in the mold [1]-[3]. The finished windings were as thick as the molds which consisted of different types including Silicon etching [5], [18]. This technique can build thick windings and they can be built directly on power ICs. However, there was still a problem of different thermal expansion coefficient values between copper and silicon when passing temperature process affecting the cracks of work. This research [2] has used SU-8 photoresist to fabricate polymer wall with silicon mold making the process more complicated due to the two times of molding. The research [9], [12] have presented photoresist polymer molded by UV lithography process which has built a 100 um -thick mold. However, the limitation of this process was that the aspectratio value of structure was made of ultraviolet which was not be able to fabricate the high aspect-ratio structure. Generally, aspect ratio can be built only 1-2 [12]. Thus, this fabrication process still requires large areas for making low- resistance winding.

Under the mentioned limitation, this research has proposed the application of x-ray lithography process to establish high aspect ratio structure with $\mathrm{x}$-ray lithography and it was the first time to take this process to fabricate micro power-inductor for DC-DC converter circuit by fabricating the inductor's winding with aspect ratio of 10 . This fabrication managed to help establish very low resistance but preserved small formfactor and low profile. Besides, this new process was taken to fabricate the inductor by embedding the inductor in SU-8 slab in form of substrate-less. The acquired structure substrate-less can be applied to additionally establish structure of both sides. This advantage will be taken to apply for fabricating magnetic's core of the pot core inductor by electroplating magnetic core forming around winding at once. In addition to complicated reduction, it was also a batch process resulted in low cost establishment process and at the end, the dc resistance, ac resistance, inductance and saturated current of the inductors has been demonstrated.

\section{INDUCTOR DESIGN}

A low resistance inductor but small form factor was the goal in fabricating the inductor. In this research, high-aspect ratio structure technology was taken to apply for x-ray lithography which was the important process making the inductor windings for DC-DC converter circuit. After consideration on three main properties including DC resistance, inductance, and saturated current, the process of design was devided into two items including the design of inductor windings and magnetic core as the following details;

\subsection{Copper Winding}

This research has chosen pot-core structure due to its small form factor and low profile. This structure has regtangular spiral winding as Figure 1. The inductor winding which was designed equal $25 \mu \mathrm{m}$ wide could print UV-mask with the laser printer. Regarding the height of winding, it was designed with aspect-ratio of 10 which was the highest ratio potentially fabricated in Micro-fabrication laboratory of synchrotron light research institute, Thailand. Thus, the $250 \mu \mathrm{m}$ - thick windings were designed. From this structure, the winding length could be calculated by Equation 1 and the value was sequentially replaced in 2 to calculate the winding resistance. With the size of mentioned structure, the resistance and the area of the inductor type 3-16 turns could be calculated as shown in Table 1 indicating the resistance of fabricated inductor in the range of 27-270 $\mathrm{m} \Omega$ using area1.8-9.5 $\mathrm{mm} 2$ which relatively low compared with literatures [1]-[15].

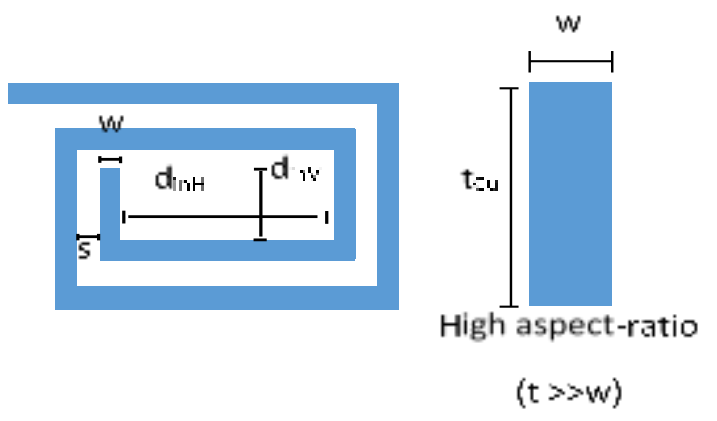

Figure 1. Copper winding dimension and calculated DC resistance of 3-16 turns inductors 


$$
\begin{aligned}
& l_{C u}=\left[2 \cdot n \cdot d_{i n V}+\left(2 n^{2}-n\right) \cdot(w+s)\right]+\left[2 \cdot n \cdot d_{i n H}+\left(2 n^{2}-n\right) \cdot(w+s)\right]+4 n w \\
& R_{D C}=\frac{\rho_{C u}}{t_{C u} \cdot w}\left[\left[2 \cdot n \cdot d_{i n V}+\left(2 n^{2}-n\right) \cdot(w+s)\right]+\left[2 \cdot n \cdot d_{i n H}+\left(2 n^{2}-n\right) \cdot(w+s)\right]+4 n w\right]
\end{aligned}
$$

Where $: l_{C u}$ : The copper winding length.

$R_{D C}$ : The winding resistance.

$n$ : The number of turns.

$d_{i n V}:$ The inner space width.

$d_{i n H}$ : The inner space long.

$s:$ The space between windings.

$w:$ The conductor width

$t_{C u}$ : The conductor height.

$\rho_{C u}$ : The resistivity of material.

Table 1. Calculated Resistance and Area of Inductor's Winding

\begin{tabular}{ccccc}
\hline Number of turns (turn) & Coil Thickness $(\mu \mathrm{m})$ & Coil width $(\mu \mathrm{m})$ & Resistance $(\mathrm{Ohm})$ & Area $\left(\mathrm{mm}^{2}\right)$ \\
\hline 3 & 250 & 25 & 27.0 & 1.8 \\
5 & 250 & 25 & 51.1 & 2.3 \\
10 & 250 & 25 & 132.3 & 5.3 \\
16 & 250 & 25 & 269.4 & 9.5 \\
\hline
\end{tabular}

\subsection{Magnetic Core}

Permalloy (Ni80Fe20) was chosen to be a material for building magnetic core of inductors. Owing to its high permeability, high saturation flux density [6], and forming by electroplating, it is suitable for microfabrication. According to the experiment finding out current suitable for electroplating, it was found that the current density of $5 \mathrm{~mA} / \mathrm{cm}^{2}$ was the maximum current not yielding bubble air inside the material and acquiring smooth material surface. And at this current density, the metal was deposited at $8 \mu \mathrm{m}$ per hour. However, as its high conductivity easily led to eddy current loss, the magnetic core had to be designed to be less thick than or equal to that of skin depth at the maximum frequency to avoid power loss. This magnetic material was taken to test the properties of permeability [19] of 550, saturation flux density of 1 Tesla and the conductivity of $5.66 \times 106 \mathrm{~S} / \mathrm{m}$. The skin depth can be calculated at $1 \mathrm{MHZ}$ equal $8 \mu \mathrm{m}$. According to this research, the inductor was designed for using at the frequency range of $1 \mathrm{MHz}$. Thus, the core, which was designed to be less thick than or equal $8 \mu \mathrm{m}$, could avoid power loss from eddy current.

The inductor structure was designed to have pot-core structure which was all surrounded by the magnetic core. Thus, it was suitable to apply the process of metal embedded SU-8 slab because magnetic core can be simultaneously electroplated in the same time to help reduce the complicated process. Furthermore, the advantage of this structure was terrmal sink since there was metal core around the inductor structure as the model in Figure 2. and substrate-less geometry could also improved the thermal reduction [19]. From this structure, the winding was designed to be $250 \mu \mathrm{m}$ high but the structure height including insulation layer and magnetic core was less thick than $400 \mu \mathrm{m}$. This was very suitable for being On-chip inductor for micro power-converter applications.

(a)

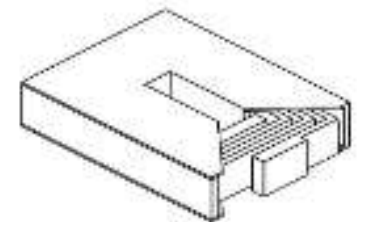

(b)

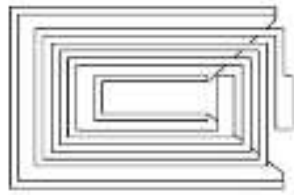

(c)

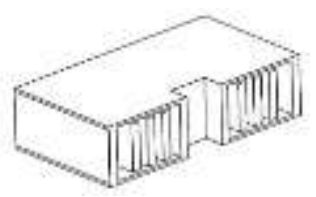

Figure 2. Model of a 3 turns inductor with 250 um thick winding. (a) 3D model, (b) Top view cross-section,

(c) Front view cross-section 


\section{INDUCTORS FABRICATION}

\subsection{Metal-embedded SU-8 Slab Fabrication Technique}

The process of inductor winding using metal embedded SU-8 slab technique, which was newly developed, had important principles including the fabrication of work on substrate as common to surface micromachining, and then the substrate was remove. Then the finished sample can be taken to build additional structure on both sides or this structure can be mounted directly on ICs. The process of establishing mold prototype was x-ray lithography process to obtain high-ratio structure. The process started from coating SU-8 photoresist with $300 \mu \mathrm{m}$-thick on Graphite substrate and then soft baked at $95 \mathrm{oC}$ for 13 hours and let sample's temperature decrease to room temperature to avoid stress inside thick SU-8 film. 50 $\mu \mathrm{m}$-thick silver mask was used for X-ray exposure and then exposed X-ray through silver mask with power of $22 \mathrm{~J} / \mathrm{cm} 3$ and soft baked for 20 minutes. Exposed sample was developed with SU-8 developer solution for 2 hours and then rinsed with acetone and DI water to clean residual SU-8. Hard baked and plasma cleaning with argon at $200 \mathrm{~mW}$ for 15 minutes. This clean and dry sample will allow good electroforming inside SU-8 mold.

The mold was filled with electroplated copper using 2 current steps, $30 \mathrm{~mA} / \mathrm{cm} 2$ for 10 minutes and then $10 \mathrm{~mA} / \mathrm{cm} 2$ until copper overfilled the mold as shown in Figure (3a). Mechanical polishing was performed for removing overfilled copper and graphite substrate. Figure (4) shows cross-sectional view of process flow and Figure (5) shows transparent embedded copper winding inside SU-8 mold. In advantage of substrate-less sample so the magnetic core can deposite around winding at once and this simplified process.

(a)

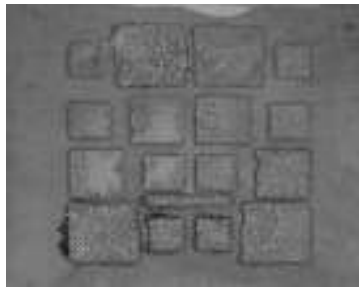

(b)

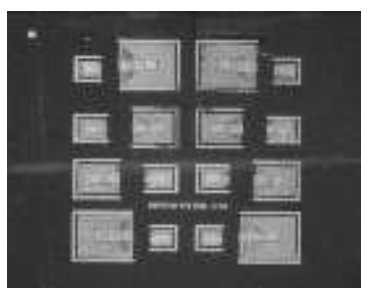

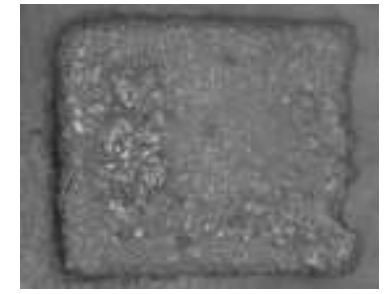

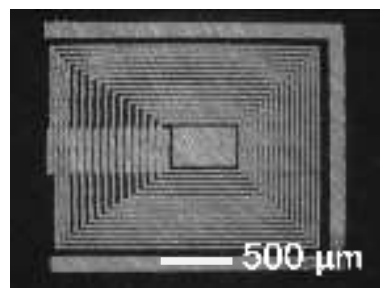

Figure 3. Electroplated and polished Copper winding embedded in SU-8 mold. (a) Electroplated copper (b) polished over-filled copper

a)

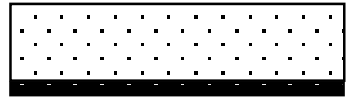

b)

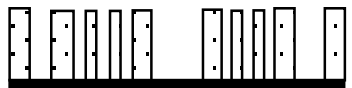

Graphite (c)

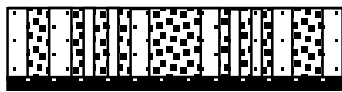

(d)

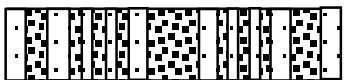

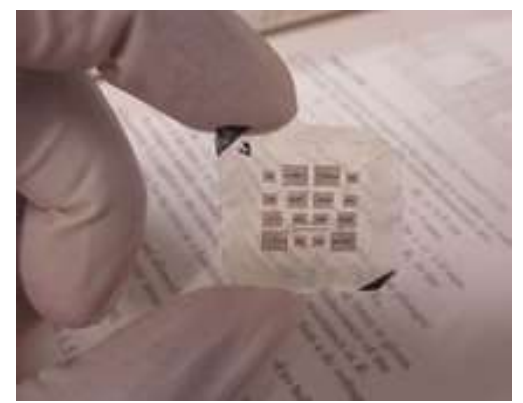

Figure 4. Cross-section view of process flow of X-ray lithography molding techniques for thick-coil fabrication: (a) $300 \mu \mathrm{m}$-thick SU-8 on graphite substrate, (b) x-ray exposed and developed, (c) Copper electroplating and polishing, (d) substrate removed

Figure 5. Transparent $250 \mu$ m-thick SU-8 slab with embedded Copper winding. 


\subsection{Magnetic Core Fabrication}

Inductor's core was fabricated by using UV lithography, electroplating, sputtering and material liftoff techniques. SU-8 and dry film are photo-sensitive materials that were used for insulating, molding and sacrificial layer. Fabrication process started with spun coating $50 \mu \mathrm{m}$-thick SU-8 photoresist on SU-8 slab then soft baking at $95^{\circ} \mathrm{C}$ for $10 \mathrm{~min}$. and then exposing UV with energy of $255 \mathrm{~mJ} / \mathrm{cm}^{2}$ through printed UV mask. After soft baking again, sample was developed in SU-8 developer to remove unexposed photoresist. This process was repeated on the other side to create etching-protect layer and also be used for insulater between winding and magnetic core as shown in Figure (6b). Chemical etching was used to etch copper in core area using Nitric acid 50\%. After etching for 10 minutes, we can get through hole for magnetic core as Figure (6c). Dry film photoresist was used as sacrificial layer for copper seed layer because this material needs to be removed before electroplating to define core deposite area. Dry-film photoresist was then coated on both sides of SU-8 slab and then was exposed to UV with energy of $25 \mathrm{~mJ} / \mathrm{cm}^{2}$, developed by Dry-film developer to remove unexposed film as Figure (6e). Copper seed layer was deposited on the whole sample by dc sputtering and then lift-off dry-film by using Acetone to define deposite areas. The sample was ready for magnetic core electroplated as shown in Figure (7b). Permalloy electroplating was performed with current density of $5 \mathrm{~mA} / \mathrm{cm}^{2}$ by using NiFe batch solution. This condition can provide deposition rate of $8 \mu \mathrm{m}$ per hour. Inductor'core fabrication process was designed for batch fabrication by using copper track as Figure (8). This track was designed to connect all cores together and also help magnetic's core for all inductors to grow at the same rate. An electroplated sample was shown in Figure (8).

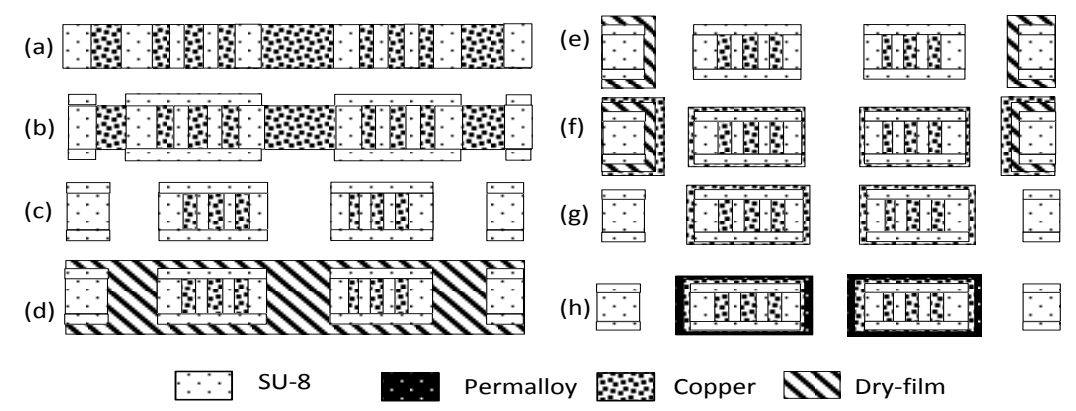

Figure 6. Cross-section view of process flow of X-ray lithography techniques for integrated micro inductors: (a) copper embedded SU-8 slab, (b) spin coating 50 $\mu \mathrm{m}$ of SU-8 photoresist and pattern SU-8 on both sides, (c) remove copper, (d) coat dry-film photoresist on both sides, (e) pattern dry-film, (f) deposit copper seed layer by sputtering,(g) lift-of dry film, (h) electroplate permalloy and then remove SU-8 on bonding pad by plasma etching

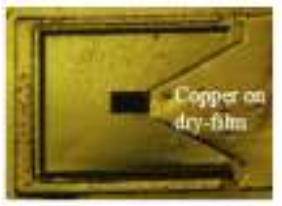

(a)

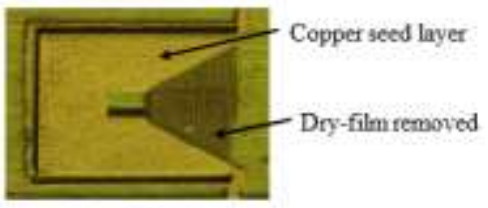

(b)

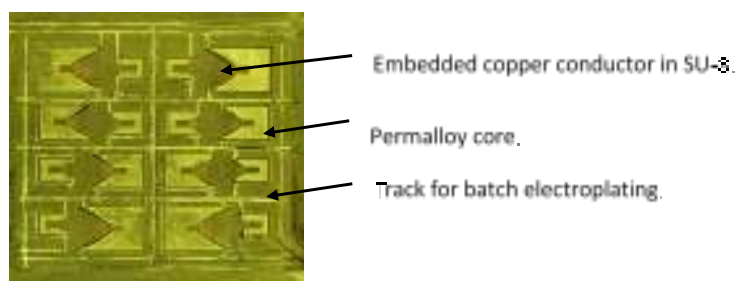

Figure 7. Fabricated 16-turns Micro-Power inductors embedded in SU-8.(a) Sputtered copper seed layer (b) Lift-off dry-film/copper

Figure 8. Batch Fabricated of micro-power inductors embedded in SU-8 slab

After fabrication had been done, the SU-8 overcoated on bonding pad was removed by plasma etching with power of $200 \mathrm{mw}$ for 3 hours, then rinsed it with sulfuric acid to remove copper oxide. This could make bonding pad clean and ready for wire bonding, Figure (9) shows completely fabricated samples and cross-section of fabricated samples that represent good dimension as expected. Althrough winding was designed as high aspect-ratio but these inductors were suitable to use as integrated or on-chip inductors beacause overall height of inductors was just only $370 \mu \mathrm{m}$ which included $250 \mu \mathrm{m}$-thick winding, $100 \mu \mathrm{m}$ of insulator, and $16 \mu \mathrm{m}$-thick of magnetic core, representing a small form factor and low profile as expected. 


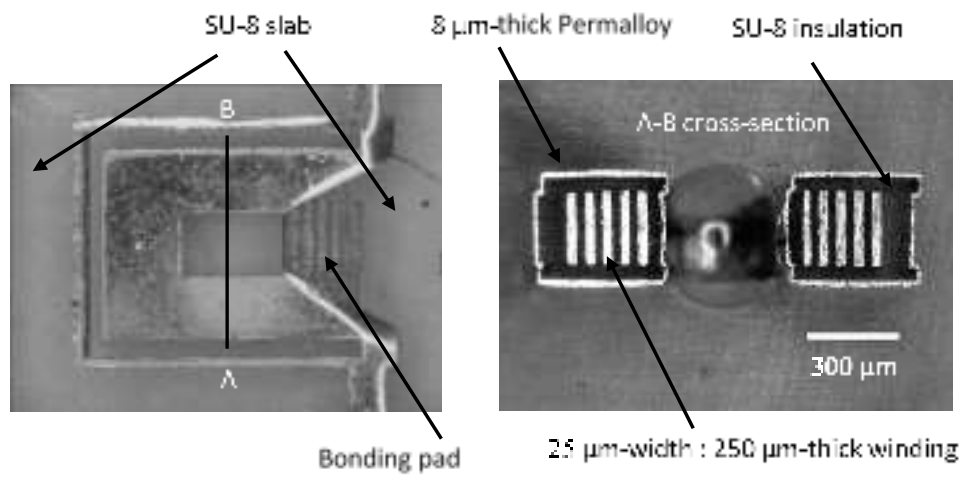

Figure 9. Fabricated 5-turns micro power-indcution and cross-section

\section{RESULT AND DISCUSSION}

The DC resistance of fabricated inductors was tested by four probe measurement method of DC resistance in the range of $29.8 \mathrm{~m} \Omega-335 \mathrm{~m} \Omega$ of the inductortype 3-16 turns respectively as shown in Table 2 . The design of high aspect-ratio winding could reduce considerable resistance. The obtained value was close to that was calculated by equation (2) but there was deviation due to the printing of UV-mask by laser printer of which the limitation was close to the structure size. By measuring the fabricated inductor's winding width, it was found that the average width was $23 \mu \mathrm{m}$. As the design was set at $25 \mu \mathrm{m}$, it resulted in the higher inductor's resistance than that of the design, especially the most turns inductor which was 16 turns having the maximum deviation. However, the inductor which was built in high aspect-ratio structure had very low DC resistance per area. At the end, it was compared with the researches [1]-[15] on the inductance and the resistance values using area as a criterion in comparison.

Table 2. Measured and Calculated DC Resistance of Fabricated Inductors

\begin{tabular}{ccccc}
\hline Inductortype & $\mathrm{R}_{\mathrm{DC} \text { Calc }}(\mathrm{m} \Omega)$ & $\mathrm{R}_{\mathrm{DC} \text { meas }}(\mathrm{m} \Omega)$ & Area $\left(\mathrm{mm}^{2}\right)$ & $\mathrm{R}_{\mathrm{DC}} \cdot \operatorname{Area}\left(\Omega \cdot \mathrm{mm}^{2}\right)$ \\
\hline 3 turns & 27.0 & 29.8 & 1.8 & 0.054 \\
5 turn & 51.1 & 51.1 & 2.34 & 0.119 \\
10 turn & 132.3 & 148.6 & 5.25 & 0.782 \\
16 turn & 269.4 & 335.6 & 9.45 & 3.16 \\
\hline
\end{tabular}

Hi-frequency charactorization was performed by using vector network analyzer Agilent 8650ES and one port scattering (S11) measurement was done in frequency range of $30 \mathrm{kHz}$ to $1 \mathrm{GHz}$ while parasitic capacitance of pad and connector were de-embedded by using admittance matrix method [21]. The selfresonance frequency was not observed in frequency range of $30 \mathrm{kHz}$ to $1 \mathrm{GHz}$ for $3-10$ turns inductors but observed at $800 \mathrm{MHz}$ for 16 turns inductor.Thus, the results of self-resonance can be considerably 10eft since the inductor was designed to work in the frequency range not over $50 \mathrm{MHz}$. The measured S11 value was taken to calculate inductance value by using L-R Series Model. The inductance value was frequency function as shown in Figure 10(a). It can be seen that the inductance value slightly decreased according to the frequency because of the reduction of permeability of Permalloy as frequency increased. At frequencies higher than $2 \mathrm{MHz}$, the inductance value decreased significantly. As the skin depth's value of magnetic core was higher than the thickness of core, the inductance value subsequently decreased in accordance with crosssectional area of magnetic core reduction.

Figure 10(b) shows the inductor resistance in function of frequency. When considering the frequency below $1 \mathrm{MHz}$, the inductor resistance value increased in accordance with frequency resulted from skin depth of high aspect-ratio winding. When considering the frequencies higher than $1 \mathrm{MHz}$, it was found that the inductance value increased rapidly due to Eddy current loss in magnetic core because its thickness was greater than that of skin depth at a frequency of $1 \mathrm{MHz}$. Thus, in case that the future research demands the task design for higher frequency the design of magnetic core should reduce thickness and be fabricated in laminate pattern to reduce Eddy current loss. 


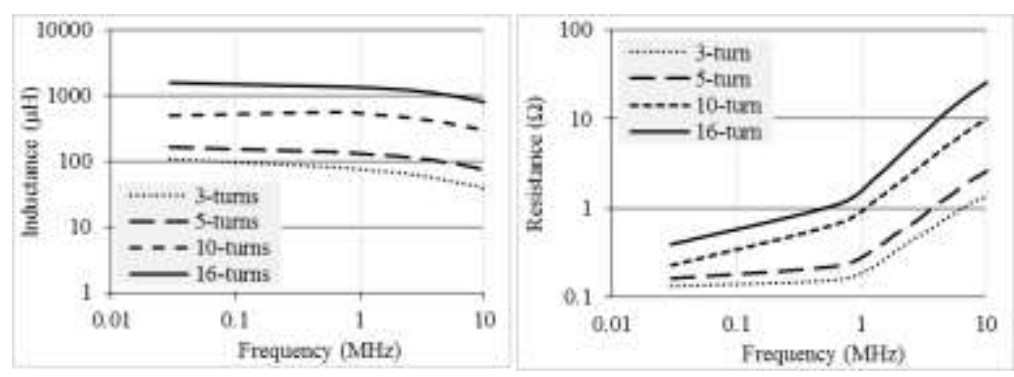

Figure 10. Measured inductance and AC resistance in a frequency range of $30 \mathrm{kHz}$ to $10 \mathrm{MHz}$

Magnetic core saturation was demonstrate by biasing the DC current in the range of 0 to $500 \mathrm{~mA}$ at frequency $1 \mathrm{MHz}$. Figure 11 shows the inductance values which are the function of bias current. The values of all inductance decrease in accordance with the increase of biased current which refers to the beginning of magnetic core saturation, that defined by the current reducing the inductance value by $20 \%$ of initial inductance. From the result, all kinds of inductors' saturated current were around $110 \mathrm{~mA}$ which was rather low. This resulted from un-gapped magnetic core structure. In case of the demand in designing work requiring higher current, the gap could be added into magnetic core structure to help increase the value of saturated current as needed.

Figure 12 shows the comparison between the inductance and DC-resistance multiplying with the area of the fabricated inductor. Compared with literature, in this research, the fabricated inductors including 3 turns and 5-16 turn inductors, when associated with the lowest areas, had very low DC resistance. It shows that the treatment of high aspect-ratio technology fabricating inductor's winding potentially helps reduce the resistance even in a small area. Regarding the inductance of fabricated inductors, their values were equal to those of other researches. In general, the inductors fabricated by high-aspect ratio associated with the process of metal embedded SU-8 techniques yield the good results including low-resistance, high inductance, and a small form factor.

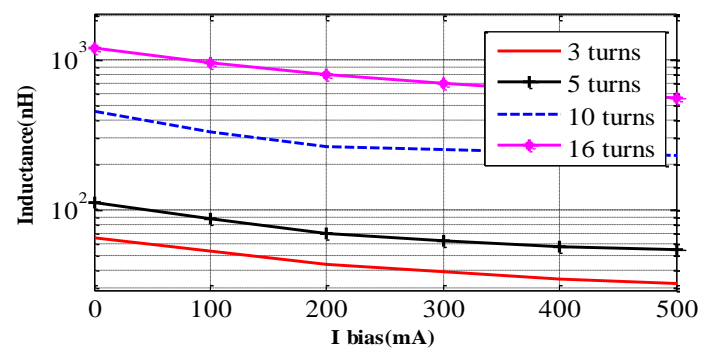

Figure 11. Measured inductance as a function of dc bias current at $1 \mathrm{MHz}$

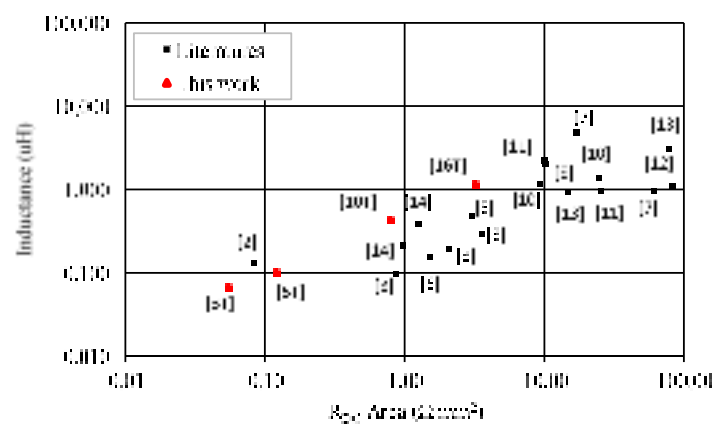

Figure 12. Inductance and resistance of fabricated inductors compared to literatures

\section{CONCLUSION}

Micromachined inductor for dc-dc converter application were fabricated by using metal embedded SU-8 slab techniques. The design of high aspect ratio winding with X-ray lithography process was applied to fabricate inductor's winding with aspect ratio of 10. This structure could help minimize DC resistance but preserve small formfactor and low profile. Nevertheless, with the advantage of metal embedded su- 8 slab techniques, the magnetic core which potentially deposited around winding at once could help simplify process and provide low cost. As the result, the measured DC resistance showed very low DC resistance as expected and lower than that of literatures when factored with inductor's area. The inductance showed comparable results but quite small saturation current because the magnetic core was configured as ungapped. For future researches, the magnetic properties and structure will be developed to acquire the high inductance with low-resistance inductors and serve the application requiring higher current. 


\section{ACKNOWLEDGEMENTS}

Thailand.

This research is fully supported by Synchrotron Light Research Institute (Public Organization),

\section{REFERENCES}

[1] N. Wang, et al.,"High Frequency dc-dc Converter with Co-packaged Planar Inductor and Power IC," in 2013Electronic Components \& Technology Conference, 2013., pp. 1946-1952

[2] M. Wang, et al., "Silicon molding techniques for integrated power MEMS inductors,"Sensors and Actuators A: Physical, 2011,vol. 166, pp. 157-163.

[3] T. O’Donnell, et al., "Microfabricated Inductors for $20 \mathrm{MHz}$ Dc-Dc Converters," in Applied Power Electronics Conference and Exposition, 2008.APEC 2008. Twenty-Third Annual IEEE, 2008, pp. 689-693.

[4] N. Wang, et al., "Micro-inductors integrated on silicon for power supply on chip," Journal of Magnetism and Magnetic Materials, 2007, pp. 233-237.

[5] B. Orlando, et al., "Low-Resistance Integrated Toroidal Inductorfor Power Management," IEEE Transactions on Magnetics, vol. 42, pp. 3374-3376, 2006.

[6] N. Wang, et al., "High-frequency Micro-machined Power Inductors," ," Journal of Magnetism and Magnetic Materials, vol. 290-291, part 2, pp. 1347-1350, Apl 2005.

[7] F. Sato, et al., "All-in-One Package Ultracompact MicropowerModule Using Thin-Film Inductor," IEEE Transactions on Magnetics, vol. 40, pp. 2029-2031, Jul 2004.

[8] Y. Fukuda, et al., "Planar Inductor With Ferrite Layers forDC-DC Converter," IEEE Transactions on Magnetics, vol. 39, pp. 2057-2061, Jul 2003.

[9] E. Brandon, et al., "Fabrication and Characterization of Microinductors for Distributed Power Converters," IEEE Transactions on Magnetics, vol. 39, pp. 2049-2056, Jul 2003.

[10] J. W. Park and Mark G. Allen, "Ultralow-Profile Micromachined Power Inductors With Highly Laminated Ni/Fe Cores: Application to Low-Megahertz DC-DC Converters," IEEE Transactions on Magnetics, vol. 39, pp. 31843186, Sep 2003.

[11] K. H. Kim, et al., "A Megahertz Switching DC/DC ConverterUsing FeBN Thin Film Inductor," IEEE Transactions on Magnetics, vol. 38, pp. 3162-3164, Sep 2002.

[12] D. Sadler, et al.,"Micromachined Spiral Inductors Using UV-LIGATechniques," IEEE Transactions on Magnetics, vol. 37, pp. 2897-2899, Jul2001.

[13] H. Nakazawa, et al., "Micro-DC/DC Converter that Integrates PlanarInductor on Power IC," IEEE Transactions on Magnetics, vol. 36, pp. 3518-3520, Sep2000.

[14] C. H. Ahh and M.G. Allen,"Micromachined Planar Inductors on Silicon Wafers for MEMS Applications," IEEE Transactions on Industrial Electronics, vol. 45, pp. 866-876, Dec 1998.

[15] [15] M. Saidanai and M. A. Gijs,"Cubic Millimeter Power Inductor Fabricated inBatch-Type Wafer Technology,"Journal OfMicroelectromechanical Systems, VOL. 12, NO. 2,pp. 172-178, APRIL 2003

[16] G. Schrom, et al.,"A 100MHz Eight-Phase Buck Converter Delivering12A in 25mm2 Using Air-Core Inductors," Applied Power Electronics Conference, APEC 2007- Twenty Second Annual IEEE, pp. 727-730, Feb 2007.

[17] P. Deekla, et al., " Al Microheater and Ni Temperature Sensor Set based-on Photolithography with Closed-Loop Control," International Journal of Electrical and Computer Engineering, vol. 5, No 4, pp. 849-858, Aug 2015.

[18] M. Wang, et al., "SU8 Enhanced High Power Density MEMS Inductors," in 2008 Proc. of the 34th Annual Conference of the IEEE Industrial Electronics Society 2008., pp. 1946-1952

[19] O. Caltun, et al., "Initial permeability, hysteresis and total losses measurements," in AnaleleStiintifice-FizicaStarii Condensate 2000, pp. 56-60.

[20] Y. Benhadda, et al., " Thermal Behavior of an Integrated Square Spiral MicroCoil," Indonesian Journal of Electrical Engineering and Computer Science, vol. 14, No 2, pp. 250-265, May 2015.

[21] S. Linder, "S-parameter techniques for faster, more accurate network design," HP application note 95-1, Hewlett Packard 1996.

\section{BIOGRAPHIES OF AUTHORS}

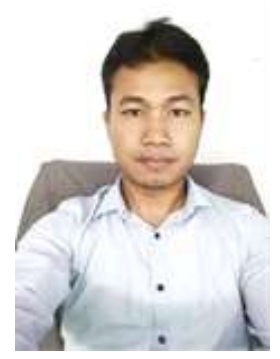

Manot Mapato received his B.Eng. and M.Eng. from Suranaree University of Technology, Nakhon Ratchasima, Thailand in 2005 and 2007, respectively, both in Electrical Engineering. With financial support from the Synchrotron Light Research Institute (Public Organization), he is currently working toward the Ph.D. degree in the School of Electrical Engineering, Institute of Engineering, Suranaree University of Technology. His research interests include X-ray lithrography application, micro-sensor, micro-electronics devices and embedded control system. 

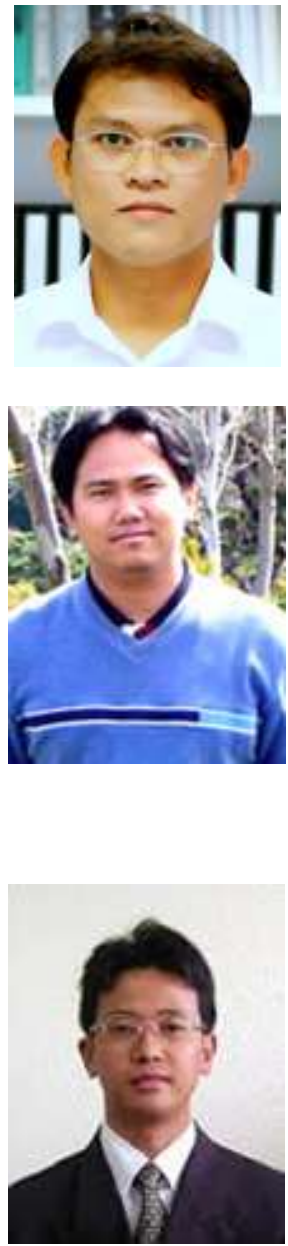

Prapong Klysubun received his B.Sc. (Hons) degree in physics from Chulalongkorn University, Bangkok, Thailand, in 1996, and his M.Sc. and Ph.D. degrees in physics from Virginia Polytechnic and State University (Virginia Tech) in 1998 and 2002, respectively. After graduation, he started working as a researcher at Synchrotron Light Research Institute (formerly known as National Synchrotron Research Center). He is currently serving as an Assistant Director and the Director of Accelerator Technology Division of SLRI. His research interests include accelerator physics, particle beam dynamics, and applications of synchrotron radiation.

Thanatchai Kulworawanichpong received his B.Eng. from Suranaree University of Technology, Nakhon Ratchasima, Thailand in 1998 and his M.Eng. from Chulalongkorn University, Bangkok, Thailand in 2000, both in Electrical Engineering. He also got his Ph.D. from the University of Birmingham, England, 2004. His employment experience started with teaching assistant in 1998 at School of Electrical Engineering, Suranaree University of Technology. In 2000, he was promoted to be a full-time lecturer of the same school. Again, he was promoted to be an associate professor of electrical engineering as his current position up-to-now. He became a member of several well-known academic societies, such as, WSEAS, IEEE, IET, IEEJ, WASET, IASTED, etc. Also he has usually served these societies as their referee for reviewing submitted papers to their journals. His special fields of interest included electrical machines, power electronic control and drives, soft computing, modeling and simulation with advanced numerical techniques, and electrical power system analysis.

Nimit Chomnawang received the B.Eng. degree in instrumentation engineering from King Mongkut's Institute of Technology, Ladkrabang, Thailand, in 1993, the MS degree in biomedical engineering from Virginia Commonwealth University in 1999, and MS and $\mathrm{PhD}$ degrees in electrical engineering from Louisiana State University in 2001 and 2002, respectively. Since 2002, he has been a lecturer at the School of Electrical Engineering, Suranaree University of Technology, Thailand. His research interests include microfabrication, MEMS, biomedical instrumentation, and embedded automation. 